from the lowest stratum would at the second stratum be joined by the bubbles formed here, and at the third stratum by a third set of bubbles, and at the hundredth stratum there would be a set of bubbles together generated in a hundred strata. Thus, in the hundredth stratum, there would be a hundred times as many bubbles as in the lowest stratum; and, if the process went on uninterruptedly, these relative numbers would be constantly present. The phenomenon is best demonstrated on champagne; and the regular followers of science could not resist even my explanation derived from so plausible a rnaterial. Now, if Dr. Jones will try the experiment upon a bottle, the last glass will quite convince him of the correctness of my explanation. It requires repeated examination to find that the many bubbles in the upper strata are not all generated there, but have only risen to that position from lower spheres. Dr. Jones is evidently under a misconception when he assumes the drachm of urine not to be thoroughly mixed; for, on the addition of liquor to the drachm of urine, the liquor must sink to the bottom, as being of the highest specific gravity ;* and the urine must rise, and permit all subsequent portions of liquor to pass through its substance. And then the tube is inverted, and, should any urine be left unmixed, it would have to go to the top again; hereby, and by the rapid evolution of gas, the fluid is brought into such a commotion that it must be most intimately mixed. Indeed, if neither the different specific gravities nor the commotion caused by the gas did effect an intimate mixture, the mere act of pouring ten, or twenty, or more parts of the liquor down a long tube, to one part of urine, would speedily effect a mixture; and, if that mixture was not effected in the manner I have described, it could not be effected at all, because, if the urine could ever be at the top of a column of the liquor, it must remain there, in virtue of its lower specific gravity, and could not on any account descend in the manner described by Dr. Jones.

I have made only a limited number of analyses by Dr. Davy's method, but never found any inconvenience from the mercury, such as Dr. Jones asserts that he has met with. A friend of mine, who has made many hundred analyses in this way, never observed the mercury being driven violently out and scattered about, and cannot account for this singular mishap to Dr. Jones, which caused him to adopt his first modification.

I hope Dr. Jones will continue his researches with improved methods. He has rare opportunities, and, being a pathologist, might turn them to good account. The fact of such a man applying himself to chemical analysis is an illustration of the turn which medicine is taking. We have had a great deal of pure chemistry: what we want now is chemistry applied. Applied to medicine, chemistry can only be by the profession itself, otherwise there will be no end of conflicts. If, then, the older members of the profession do not find application to quantitative analysis quite easy, they must not be astonished at it, for it took their junior colleagues years of practical study in the laboratory, and not a little reading and headwork, to attain the little which they can call their own. That ground it is their duty carefully to weed and cultivate, in order to come up to the expectations of those well versed in science, who assert that, in a short time, no physician would be able to give an opinion unless he be a microscopist and a chemist.

\section{CASE OF FEMORAL HERNIA.}

By Edwari) A. Brown, Esq., Surgeon, Eastwood.

Aт 12 o'clock on the night of Friday, June 27 th, I was sum moned to attend Mrs. G., a near neighbour residing at Eastwood, suffering from strangulated femoral hernia, brought on by sudden and unusual exertion. The symptoms were well marked and severe. The pulse was irritable, about 90 . There were anxiety of countenance, vomiting of bile and mucus, and distressing pain referred over the entire abdomen. She was placed in the usual position, with the thigh of the affected side rolled inwards towards the opposite one; and the taxis was applied in the direction downwards, backwards, and upwards, for twenty minutes, ineffectually. An ordinary stimulating enema was then ordered; effervescing medicine, with hydrocyanic acid and an opiate, were prescribed; and the case was left till the following morning.

* 1.034, according to the "Dublin Pharmacopœia". The "London Pharmacopœia" gives no determined specific gravity of its preparation. The liquor, obtained from Mr. Morson, of Southampton Row, I found to have the specitic gravity of 1.043 .
June 28th, 8 A.r. There was no improvement, though the symptoms were somewhat masked by the anodyne. There had been no evacuation by the bowels. She had obstinate vomiting, increasing pain, anxious and distressed countenance. The taxis was again employed, with the use of warm bath, unsuccessfully, for twenty-five minutes, this being as long as the tenderness of the sac would admit of. Continue medicines.

2 P.м. Reduction was again ineffectually attempted.

8 P.M. There was no improvement; the symptoms were becoming aggravated. The taxis was used half an hour, under. the influence of chloroform, unsuccessfully. The patient was left for the night.

June 29th, 8 A.Mr. There was constant stercoraceous vomiting, excessive pain and dragging all over the abdomen, eructation, hiccough, and tympanitis. The bowels had not acted; the pulse was hard, wiry, 140. It being now high time to afford relief if possible, the operation was proposed, and acceded to.

There being only an old woman and myself present, the inconvenience of giving chloroform and operating can readily be conceived, especially in a cramped up chamber, and with bad light. The patient, moreover, being naturally weakly, and further reduced by suffering, it was not wise to overdo the administration of chloroform; the consequence was, that she occasionally came to, which delayed the steps of the operation. Making the usual incisions, and dividing the several coverings down to the sac, I proceeded at once to open it, numerous adhesions around quite preventing it from being returned. I found the neck tightly embraced; the bowel was of a chocolate colour, and the vessels circulating on its surface were greatly congested. On dividing upwards, and very slightly inwards, a portion of Poupart's ligament, the return of the hernia could not be effected; and the stricture was evidently caused by Gimbernat's ligament. The bowel was also punctured with a grooved needle, and the flatus expelled to afford relief, but without effect. On carefully exploring the opening with the finger-end, distinct pulsation could be felt, from an irregular distribution of the obturatrix artery surrounding the inner part of the neck of the sac; and, being indisposed to risk its division, having oiled the forefinger, I gradually dilated the opening, and was pleased to find the method quite successful, the bowel being returned without much difficulty.

I ordered an enema of warm gruel, a dose of castor oil, and a mild mercurial purge. The bowels were freely acted on. Her symptoms were materially relieved, though peritonitis supervened: this, however, fortunately gave way readily to treatment, and everything progressed to a favourable issue.

November 3rd. Not the slightest inconvenience has arisen since the operation; and she speaks of the affected side being stronger and more comfortable than the opposite one. I have not the least doubt of the obliteration of the weakened aperture. She has for a corisiderable time been taking her ordinary food, and follows her ordinary avocation, being quite well. One of Huxley's elastic abdominal belts, with air-pad, has been supplied, and affords great support and comfort.

REMARKS. The process of mechanical dilatation acted in this case most favourably.

1. The risk of wounding the obturatrix artery was removed.

2. The part itself was not so weakened subsequently as by division with the knife.

3. Although, if too roughly handled, the gut might be bruised, in the absence of this, inflammatory action may take place around the neck of the sac, causing effusion of lymph and a repair of the otherwise weak points of the parietes. In the present case, I fully believe this has actually occurred.

\section{THE TREATMENT OF ACUTE RHEUMATISM.}

By Henry William Fuller, M.D.Cantab, F.R.C.P., Physician to St. George's Hospital.

Dr. Inman's article on the treatment of acute rheumatism, inserted in our Jounnal on October 24th, demands a passing notice. Its quotations are incorrect, its statements of a strangely perplexing nature, and its conclusions at variance with the result of observations in London, Liverpool, and elsewhere.

And, firstly, as to Dr. Inman's quotations, or rather the statements and opinions he purs into my mouth. "Dr. Fuller," he says, "gives as the average duration of his cases five weeks." How far this quotation is consistent with accuracy may be 
judged by the following passages from my work on Rheumatism. "My own observation has led me to believe that even when unattended by any interral affection, the disease, under ordinary methous of treatment, endures from four to five weeks. Of the 246 cases admitted into St. George's Hospital under the care of the physicians during the time I held the office of Hedical Registrar, the great majority were convalescent about the end of the fourth or the beginning of the fifth week from the commencement of the attack, and were ready to leave the Hospital about the end of the sixth week; and of 23 other cases, part of which I noted in the Hôtel Dieu at Paris, and part at Addenbrooke's Hospital, at Cambridge, considerably above one half were of about the same duration. Experience, however, has taught me to believe that remedial agents are eapable of still further shortening its duration; and to such an extent does this hold good, that as I hope to show the average duration of an uncomplicated attack may be reduced, by judicious treatment, from a month or five weeks to ten days or a fortnight." (pp. 69 and 70, Second Edition). And again at p. 137, after analysing the result of 85 cases, treated after the plan I have recommended, I state, "The articular inflammation subsided altogether within twenty-four hours in 2 instances; within forty-eight hours in 10 instances; within three days in 17 instances; within four days in 12 instances; within five days in 9 instances; within seven days in 6 instances; and in the remaining 12, althongh it did not wholly subside until a later period, yet it did not display any symptoms of activity after the fourth day."

Dr. Inman's next assertion is: "Dr. Fuller states that he has found those cases progress the most favourably in which the sour smelling perspirations are most abundant." Now this crude statement entirely misrepresents my views on the subject. Those cases, of course, in which profuse sour-smelling perspirations occur, are those which are most severe, and therefore less readily brought under the influence of remedies; but in discussing the effect of the profuse perspirations which do occur in the most severe forms of the disease, and which alone I term "acute rheumatism" or "rheumatic fever", I state, as the result of my observation of the disease under different modes of treatment (p. 65), "The cases of rheumatic fever which have progressed most favourably, which, though severe in their local and general symptoms, have run their course in a fortnight or three weeks, and have left the patient free from pain, have been those accompanied by profuse acid perspirations; whilst those which, in spite of treatment, have lingered on for a period of six or eight weeks, have been those in which the sweating has been less strongly acid, less perfect in its development, or less constant in its continuance, taking place over a portion only of the body, or occurring profusely perhaps for two or three days, and then subsiding or altogether disappearing. In this statement I am satisfied that the profession will bear me out; but of course it applies only to cases of really acut rheumatism, and not to such cases as Dr. Inman speaks of-cases in which he tells us that "a dry skin and comparatively clean tongue was the rule"; but which, nevertheless, he is pleased to term cases of acute rheumatism. If such cases as those spoken of by Dr. Inman are to be termed cases of acute rheumatism, our whole nomenclature must be altered.

Dr. Inman then proceeds to say: "Dr. Fuller considers it advisable to give a daily aperient." My statements are (p. 86) "I must express my dissent from the practice of repeated active purging." Again (p. 88) : "In cases in which the bowels are acting freely, and the dejections are healthy and bilious in appearance, purging may be useful as a powerful means of drawing off the poison; but it certainly is unnecessary for the cure of the disease." Again, at p. 109, when discussing my own plan of treatment, I say, "If the bowels are acting once a day, it is seldom necessary to make a more frequent call upon their activity"; and in neither of the six cases which I have quoted in detail (pp. 117-133) have I ordered more than an occasional aperient. In the first case I ordered an aperient once only throughout the attack; in the second, twice; in the third, three times; in the fourth, three times; in the fifth, twice: in the sixth, once only. So much for my considering "it advisable to give a daily aperient."

Dr. Inman, however, is a most successful practitioner. $\mathrm{He}$ has had thirty cases of acute rheumatism under his care, has given lemon juice in all, and has "found it do good in all"; indeed, the average duration of his cases "has been about ten days", and "the longest case he has had has been three weeks". Truly may he say that there must be a wide difference between his cases and those reported in London and elsewhere. It was
Dr. Owen Rees who first introduced lemon-juice to the notice of the profession as a remedy for acute rheumatism, and no one knows better how to employ it; yet the cases he has reported, on the average, were twenty-five days under treatment, and were ill for a period of forty days; whereas Dr. Inman, with the same remedy, cures the average of his cases within the space of ten days! But then in Dr. Rees' cases "profuse sweating" was not quite "the exception", nor "a dry skin and comparatively clean tongue the rule". The profession has been taught to regard such cases, whether with or without some swelling of the joints, as instances of subacute or chronic rheumatism; and Dr. Rees would not term them acute rheumatism, even for the sake of reporting them as speedily cured.

\section{THE TREATMENT OF ACUTE RHEUMATISM.}

By Arthur B. Steele, Esq., Liverpool.

As my experience of the effects of lemon-juice in acute rheumatism does not coincide with that of my talented fellow-townsman, Dr. Inman (see British MedicaI Journal, October 24th, p. 883), I am induced to record a brief summary of the opinions and mode of treatment I have adopted in reference to that disease.

Acute rheumatism appears to have a tendency to run a definite course, analogous to that of the exanthemata; and the duration of the attack is probably not so much dependent on the peculiar treatment adopted as has generally been supposed. This, I think, will in some measure explain how it is that similar results are obtained by such rery opposite modes of treatment.

When I was a student at St. George's Hospital, the plan adopted by Dr. Seymour was bleeding and purging, followed up by the guiacum mixture of the Pharmacopaia, with an opiate at bedtime, if required. This was found very successful, and marked relief was usually obtained on the second day. Various other methods might be mentioned, all apparently affording the same measure of success. I will just name cinchona, nitre in large doses, alkalies, and colchicum, each of which has found its admirers. The course I pursue in the treatment of acute rheumatism, and which I have found to answer my expectation, is this :- first, a dose of calomel, followed by a saline purgative: and then a grain of opium every two hours, until relief from pain is procured, keeping it up at longer intervals as the pain gradually subsides. As soon as the acute stage has passed, iodide of potassium and tonics are commenced. I generally find that the pain is much relieved in from twenty-four to forty-eight hours, and that a considerable abatement of the symptoms occurs from the third to the fifth day. Cardiac complication is rare, and has always yielded to local depletion and mercury except in one case in which extensive pericarditis and endocarditis existed at the time when the patient came under my care, and which ran a rapidly fatal course. The advantages of the opium plan of treatment are, that it does not depress the patient, and it affords relief to the prominent symptom-pain-with certainty and rapidity; and the recoveries, as far as my observation goes, are as speedy and favourable as under any of the various plans which have been suggested.

I have not been able to obtain any very satisfactory results fron: lemon-juice, and have therefore ceased to place reliance upon it; but it is important to bear in mind that my patients were chiefly mechanics, iron-moulders, dock labourers, etc., treated at their own dwellings, and therefore under circumstances in every respect much less favourable for testing the efficacy of the remedy than would be obtained in the wards of a hospital.

In several cases I have noticed an affection of the heart which appears to be distinct from the ordinary inflammatory cardiac amplication. It is characterised by severe pain in the præcordial region, and is liable to be mistaken for incipient endocarditis. The heart's action is tumultuous, and the sounds obscured; but no bruit is heard. I regard it as rheumatic affection of the muscular substance of the heart, unaccompanied by any organic change, but interfering with its action as we find to be the case in some of the voluntary muscle which become the seat of a mere pain, without any manifest alteration of structure. A few leeches and an opiate have always removed this symptom. 